\title{
Efeito do teor de matéria orgânica do solo, cultura de cobertura e sistema de plantio no controle de Pratylenchus brachyurus em soja
}

\author{
Mauro Junior Natalino da Costa ${ }^{1 *}$, Rodrigo Marcelo Pasqualli ${ }^{2}$, Rafael Prevedello ${ }^{2}$
}

\begin{abstract}
${ }^{1}$ Univag-Centro Universitário. Várzea Grande, MT. CEP 78.110-500. ${ }^{2}$ Fundação Rio Verde. Lucas do Rio Verde, MT. CEP 78.455-000.
Autor para correspondência: Mauro Junior Natalino da Costa (maurojunioragronomo@hotmail.com)

Data de chegada: 02/10/2013. Aceito para publicação em: 03/02/2014.
\end{abstract}

1936

\section{RESUMO}

Costa, M.J.N.; Pasqualli, R.M.; Prevedello, R. Efeito do teor de matéria orgânica do solo, cultura de cobertura e sistema de plantio no controle de Pratylenchus brachyurus em soja. Summa Phytopathologica, v.40, n.1, p.63-70, 2014.

No controle do nematoide das lesões (Pratylenchus brachyurus), têm sido indicadas algumas estratégias visando redução dos níveis populacionais, e outras que estimulam o desenvolvimento radicular, assim, objetivou-se, neste trabalho, identificar os benefícios das interações entre culturas de cobertura, teor de matéria orgânica do solo e sistemas de plantio. Foram escolhidas 2 áreas com infestação natural do nematoide e implantadas as culturas de cobertura Crotalaria spectabilis, Pennisetum glaucum (milheto ADR 300), Brachiaria decumbens, milho (híbrido 'Formula'), além de tratamentos com e sem capina química. A testemunha foi o alqueive (capina periódica). O plantio das coberturas foi realizado no dia 22/02/2010, e, no dia 3/11/2010, foi implantada a cultura da soja. Cada ensaio contou com parcelas de $6 \mathrm{~m}$ e 10 linhas (espaçamento de $0,45 \mathrm{~m}$ ). O delineamento utilizado foi o de blocos ao acaso, com 4 repetições. Como sub parcelas, foram utilizados o plantio direto e o convencional da soja e das coberturas, com a utilização de uma grade aradora. As avaliações constaram de massa seca de culturas de cobertura, níveis populacionais de nematoides, massa verde de raízes, massa seca de parte aérea e rendimento de grãos. De acordo com os resultados obtidos, a matéria orgânica do solo apresentou benefícios, com diminuição da taxa de multiplicação de $P$. brachyurus, além disso, houve interação com a cultura de cobertura e o método de plantio. O plantio convencional reduziu os níveis de infecção nas avaliações até 40 dias após a emergência (40 DAE), contudo, na avaliação seguinte (70 DAE), os níveis no plantio direto foram menores, evidenciando atributos positivos desta técnica de plantio. Dentre as culturas de cobertura, C. spectabilis apresentou maior antagonismo a $P$. brachyurus. A testemunha capinada e a capina química evitaram a multiplicação, mas o nematoide manteve níveis suficientes para causar prejuízos.

Palavras-chave adicionais: nematoide das lesões, manejo cultural, dinâmica populacional.

\section{ABSTRACT}

Costa, M.J.N.; Pasqualli, R.M.; Prevedello, R. Effect of soil organic matter content, cover crop and planting system on the control of Pratylenchus brachyurus in soybean. Summa Phytopathologica, v.40, n.1, p.63-70, 2014.

To control the root-lesion nematode (Pratylenchus brachyurus), some strategies have been recommended with the aim of reducing the population levels and others, with the aim of stimulating root development; thus, the aim of this study was to identify the benefits of interactions among cover crops, organic matter content and planting systems. The two chosen areas had natural infestation with the nematode, and the cover crops Crotalaria spectabilis, Pennisetum glaucum (pearl millet ADR 300), Brachiaria decumbens, corn ('Formula' hybrid), were established, as well as treatments with and without chemical weed. The control was the fallow (periodic weed). Cover crops were planted on 22/2/2010 and the soybean was sown on 3/11/2010. Each assay included plots of $6 \mathrm{~m}$ and 10 rows ( $0.45 \mathrm{~m}$ spacing). The adopted design was in randomized blocks, with 4 replicates. As subplots, we used direct and conventional planting of soybean and cover crops by means of a large harrow. Evaluations consisted of cover crop dry mass, nematode population levels, root fresh mass, shoot dry mass and grain yield. According to the obtained results, the soil organic matter had benefits and a decrease in P. brachyurus multiplication; moreover, there was an interaction with the cover crop and the planting method. Conventional planting reduced the infection levels at the evaluations up to 40 days after emergence ( $40 \mathrm{DAE}$ ); in the subsequent evaluation (70 DAE), however, the levels for direct planting were lower, evidencing positive attributes of this planting technique. Among cover crops, $C$. spectabilis showed greater antagonism to P. brachyurus. Control weed and chemical weed prevented the multiplication, but the nematode was maintained at sufficient levels to cause damage.

Additional keywords: root lesion nematode, crop management, population dynamics.

As espécies do gênero Pratylenchus Filipjev (nematoides das lesões radiculares), são parasitas de dezenas de espécies vegetais e no Brasil, encontram condições favoráveis ao desenvolvimento, disseminação e sobrevivência, devido aos fatores edafo-climáticos, como citado por Altmann (1), Asmus (2), Costa (4) e Goulart (10).
Atualmente, $P$. brachyurus Filipjev \& Schuurmans Stekhoven, $P$. zeae Graham e $P$. coffeae Filipjev \& Schuurmans Stekhoven são as espécies que causam as maiores perdas, segundo Goulart (10), com ampla distribuição geográfica e grande número de plantas hospedeiras.

As perdas na cultura da soja (Glycine max (L.) Merr.) causadas 
pelo $P$. brachyurus são estimadas por Dias et al., (7) em 30\%. Estas perdas, contudo, são muito dependentes dos níveis populacionais, como observado por Asmus (2), Costa (4), Goulart (10) e Inomoto \& Asmus (13). Este nematoide possui habilidades de sobrevivência em restos culturais e, para Costa (4), é necessário utilizar-se de duas estratégias básicas na sustentabilidade da produção, que são a redução de níveis populacionais e o estímulo ao desenvolvimento radicular das culturas, numa convivência com esses parasitas.

Assim, as culturas de cobertura constituem alternativa promissora para o combate destes parasitas, como citam Rodriguez-Kábana \& Canullo (21). Os autores observam que podem-se utilizar as plantas armadilhas (há penetração, mas o nematoide não completa o seu desenvolvimento), maus hospedeiros (há penetração, mas poucos nematoides se desenvolvem) e aquelas que contêm compostos nematicidas e nematostáticos em seus tecidos, que podem ser liberados no meio externo.

Rodriguez-Kábana et al. (22) também relatam a produção de substâncias tóxicas, provindas da decomposição, o antagonismo, através do desenvolvimento intenso de microrganismos e também a possibilidade da matéria orgânica alterar a fisiologia do hospedeiro, o que resulta em maior resistência ao desenvolvimento do nematoide nas raízes.

Segundo Yagi et al. (26), a escolha de culturas de cobertura, em que a composição química dos resíduos apresente qualidade nutricional, pode contribuir para a qualidade da matéria orgânica do solo. Vale ressaltar, porém, que a utilização de matéria orgânica e resíduos agrícolas de forma isolada pode não ser suficiente para o manejo de nematoides, necessitando utilizar uma interação de estratégias como descrito em McSorley (18).

Estudos de espécies de culturas de cobertura foram realizados por Inomoto et al. (14); Machado et al. (17) e Ribeiro et al. (20), indicando aquelas que apresentam baixo fatores de reprodução do nematoide das lesões. Há indicações de espécies de crotalárias, milheto e outras culturas de coberturas com baixos fatores de reprodução deste parasita.

Outro método para controlar o nematoide, mas que vem sendo pouco estudado, é o alqueive, que, segundo Inomoto (12), consiste em preparar o solo por meio de aração e/ou gradagem por certo período de tempo, deixando este, sem qualquer tipo de vegetação, para que o nematoide não se desenvolva. Dessa forma, os nematoides morrem por inanição (falta de planta hospedeira), por dessecação e pela ação da luz (a faixa ultravioleta tem propriedades nematicidas).

A integração de culturas de cobertura e sistemas de plantio pode permitir maior espectro de controle, assim, Debiasi et al. (5) avaliaram culturas de cobertura e sistemas de plantio, no desenvolvimento de $P$. brachyurus. Maior produtividade de soja foi obtida por meio do alqueive mecânico (gradagem leve e aplicações de herbicidas), o qual diferiu das culturas de cobertura Brachiaria brizantha 'Marandu', milho e alqueive químico. Os autores, no entanto, recomendam a utilização de Crotalaria spectabilis e C. ochroleuca como opções para reduzir a população de $P$. brachyurus na entressafra, tendo-se em vista os efeitos negativos do revolvimento sobre a qualidade do solo.

Assim, este trabalho teve como objetivo estudar o controle de $P$. brachyurus, na cultura da soja, em dois ensaios estabelecidos em locais distintos quanto aos teores de matéria orgânica do solo e diferentes culturas de cobertura, implantadas em plantio direto e plantio convencional.

\section{MATERIAL E MÉTODOS}

Estabelecimento das culturas de cobertura em função de níveis de matéria orgânica do solo

Foram estabelecidos 2 ensaios em locais distintos quanto aos níveis de matéria orgânica (20 cm de profundidade) na Fazenda Carla, localizada no município de Lucas do Rio Verde, MT. Os níveis de matéria orgânica correspondiam a 1,8 e 3,5\%. As coordenadas geográficas, obtidas por meio de GPS, eram de 12\%49'40.13”S, $56^{\circ} 03^{\prime} 07.86^{\prime \prime} \mathrm{O}$ e $404 \mathrm{~m}$ para a área do ensaio I, e para a área do ensaio II de 1250'28.50''S, 5603'18.88'O e $406 \mathrm{~m}$.

O solo é classificado como Latossolo Vermelho Amarelo Distrófico. A análise de solo das 2 áreas forneceu as informações da fertilidade e textura (Tabela 1). No cálculo de calagem, de acordo com o método de saturação por bases do solo, determinaram-se as seguintes quantidades necessárias de calcário para as áreas I e II: 1,7 e 0,75 toneladas ha ${ }^{-1}$. Utilizou-se V2 de $55 \%$ e a aplicação de calcário foi realizada apenas antes da implantação das coberturas de solo, no dia 14/02/2010 (2 safra de 2009/10).

Nos locais escolhidos, havia incidência natural de $P$. brachyurus. As amostragens iniciais no local dos ensaios apresentaram em média 791,5 indivíduos (juvenis + adultos)/200 cc de solo na área I (CV: 17,8 \%) e 690,8/200 cc de solo na área II (CV: 15,4\%) (sendo, portanto, $13 \%$ menor que na área I). Essas médias representam variabilidade na incidência de nematoides, contudo, a distribuição dos nematoides foi considerada uniforme, pois não houve amostras com valores discrepantes o suficiente para comprometer a qualidade do trabalho, dentro de uma quantidade de 20 amostras para cada local (variação de 721 a 862 na área I e de 637 a 744 na área II). O Laboratório da Fundação Rio Verde foi utilizado para a determinação de nematoides e o Laboratório Solo Certo (Lucas do Rio Verde/MT) para análise de solo.

\section{Extração de Pratylenchus brachyurus de amostras de solo}

A extração de nematoides do solo foi realizada pelo método de decantação-peneiramento como em Flegg \& Hooper (8), combinado ao de centrifugação de Jenkins (16) e a extração de nematoides das raízes pelo método de liquidificador-peneiramento de Coolen \& D'Herde (3) combinado ao de centrifugação. Utilizaram-se $200 \mathrm{cc}$ de solo e 5 $\mathrm{g}$ de raízes. Os nematoides extraídos foram concentrados em $5 \mathrm{~mL}$ de água, através de retirada de água do recipiente, utilizando-se um sifão.

Os nematoides foram quantificados em câmara de contagem de Peters, com o auxílio de um microscópio, em duas repetições de

Tabela 1. Descrição das variáveis correspondentes à fertilidade e textura do solo das áreas onde foram realizados os 2 ensaios, sendo eles Ensaio I/Ensaio II.

\begin{tabular}{|c|c|c|c|c|c|c|}
\hline Argila & Mat & rgânica & \multirow{2}{*}{$\mathrm{pH}\left(\mathrm{H}_{2} \mathrm{O}\right)$} & $\mathrm{K}$ & $\mathbf{P}$ & $\mathbf{S}$ \\
\hline \multicolumn{3}{|c|}{$\%$} & & \multicolumn{3}{|c|}{$\mathrm{mg} \mathrm{dm}^{-3}$} \\
\hline $46 / 43,6$ & \multicolumn{2}{|c|}{$1,8 / 3,5$} & $5,9 / 5,3$ & $63 / 72$ & $15 / 22$ & $12,7 / 15,3$ \\
\hline Al & $\mathrm{Ca}$ & Mg & $\mathbf{K}$ & SB & CTC & $\mathbf{H}+\mathbf{A l}$ \\
\hline \multicolumn{7}{|c|}{ cmolc dm ${ }^{-3}$} \\
\hline $0,1 / 0$ & $2,75 / 3,5$ & $1,0 / 1,3$ & $0,16 / 0,18$ & $3,91 / 4,98$ & $4,81 / 5,86$ & $0,9 / 0,88$ \\
\hline
\end{tabular}


alíquotas de $1 \mathrm{~mL}$. Para a identificação de Pratylenchus sp., foram consideradas características morfológicas dos espécimens, de acordo com chaves de identificação de Gonzaga \& Soares. (9), Handoo \& Golden (11) e Tihohod (25). Com a dificuldade de separação de $P$. brachyurus e $P$. zeae, que incidem com muita frequência em um mesmo local, foi feita a leitura apenas no nível de gênero. Ressalta-se, porém, que havia uma incidência de $92,8 \%$ de $P$. brachyurus, segundo identificação realizada antes de estabelecer o ensaio.

\section{Semeadura, manejo das plantas de cobertura e delineamento experimental}

O plantio foi realizado manualmente, distribuindo-se as sementes em cerca de $30 \%$ a mais que o recomendado, sendo que após a emergência foi realizado o desbaste, permanecendo a seguinte quantidade de plantas/m linear: milho híbrido 'Fórmula': 3, Crotalaria spectabilis: 12, Brachiaria decumbens: 25 e milheto 'ADR 300': 8 (Tabela 2).

Estas coberturas foram estabelecidas sob dois critérios de sistemas de plantio, sendo o convencional, obtido através de grade aradora e plantio direto, sem revolvimento do solo. Obteve-se assim, um esquema de subparcelas $2 \times 7$, onde cada parcela de 10 linhas e $6 \mathrm{~m}$ contou com 2 sistemas de preparo de solo, de 5 linhas cada, espaçadas de $0,45 \mathrm{~m}$. Nesse caso, cada parcela útil teve eliminada 1 linha de plantio e $0,5 \mathrm{~m}$ nas extremidades, com área útil de $6,75 \mathrm{~m}^{2}$.

Utilizaram-se $150 \mathrm{~kg} \mathrm{ha}^{-1}$ de 08-20-20 (adicionados 0,4\% de $\mathrm{Zn}$ e $0,15 \%$ de B) no sulco de semeadura e $80 \mathrm{~kg} \mathrm{ha}^{-1}$ de ureia aos 25 e 40 dias após a semeadura. Os inseticidas foliares em milho foram lambdacialotrina e lufenuron, e o herbicida utilizado foi atrazina, em pré-semeadura.

A dessecação do tratamento 2 foi realizada por meio da utilização de 2,4 D + glifosato, em intervalos de 15 dias nos meses chuvosos e de 50 dias nos meses secos.

A massa seca de culturas de cobertura foi avaliada através da delimitação de 2 locais de $1 \mathrm{~m}^{2}$ dentro de cada parcela, de onde foi coletada toda a palhada formada, seca em estufa, e logo em seguida pesada. Estas avaliações foram realizadas aos 120 dias após a semeadura das culturas. O resultado obtido foi extrapolado para 1 ha.

\section{Plantio de soja em função de sistemas de plantio}

No dia 3/11/2010, foi implantada a cultura da soja, com a cultivar 'TMG 115 RR' (suscetível ao nematoide das lesões), em toda a área de cada ensaio. A soja foi semeada no espaçamento de $45 \mathrm{~cm}$ entre fileiras, com 15 sementes $/ \mathrm{m}$ linear ( $97 \%$ de germinação e excelente vigor). Esta soja foi estabelecida sob os dois critérios de sistemas de plantio, sendo o convencional, obtido através de grade aradora e plantio direto, sem revolvimento do solo.

$\mathrm{Na}$ adubação, foram utilizados $250 \mathrm{~kg} \mathrm{ha}^{-1}$ da formulação 00-28-09 + FTE + $150 \mathrm{~kg} \cdot \mathrm{ha}^{-1}$ de supersimples $\left(18 \% \mathrm{P}_{2} \mathrm{O}_{5}+12 \% \mathrm{~S}\right)$ no sulco de semeadura. Em cobertura, utilizaram-se $50 \mathrm{~kg} \mathrm{ha}^{-1}$ de $\mathrm{KCl}(60 \%$ $\mathrm{K}_{2} \mathrm{O}$ ), aos 40 dias após a semeadura. Em tratamento de sementes, foi utilizado o fungicida fludioxonil + metalaxil-M, inoculante da bactéria
Bradyrhizobium e produto contendo micronutrientes (1,5\% cobalto e $14 \%$ molibdênio). Foram utilizados os fungicidas carbendazim no estádio fenológico V8 (para o controle da antracnose) e azoxystrobina + ciproconazol em R2 e R5.2 (para o controle da ferrugem). Os inseticidas foram lufenuron + profenofós, chlorantraniliprole + lambdacialotrina e tiametoxam + lambdacialotrina em V8, R2 e R5.2.

Avaliações do desenvolvimento da população de $P$. brachyurus e do efeito sobre a cultura da soja

Foram realizadas amostragens aos 40 e 70 dias após a emergência (40 e 70 DAE), para quantificação de P. brachyurus. Neste monitoramento, foi obtida uma amostra de solo composta de 4 subamostras retiradas de pontos do caminhamento em zigue-zague dentro da parcela. A coleta das subamostras foi realizada com trado, a uma profundidade de 0-20 $\mathrm{cm}$, na região da rizosfera das plantas, retirando-se solo e raízes e, em seguida, misturadas em balde plástico até constituírem-se em uma amostra composta e homogênea.

Cada amostra foi etiquetada e embalada em sacos plásticos e acondicionada em caixas térmicas de isopor, onde todas foram transportadas ao laboratório, sendo mantidas sob refrigeração $\left(5-7^{\circ} \mathrm{C}\right)$ até que fossem processadas. A extração e a quantificação de nematoides foram realizadas como relatado anteriormente.

Também foi avaliada a massa verde de raízes e a massa seca da parte aérea. Estas variáveis foram avaliadas por meio da coleta de 20 plantas ao acaso em cada parcela, que foram levadas ao laboratório para avaliação. O rendimento de grãos foi obtido de duas linhas centrais, com $5 \mathrm{~m}$ de comprimento. Após a trilha, extrapolou-se para um hectare, considerando-se a umidade padrão de $13 \%$.

Os resultados obtidos em cada ensaio foram submetidos à análise de variância e a comparação de médias foi feita pelo teste de Tukey ( $5 \%$ de probabilidade).

As condições climáticas registradas no período de condução dos ensaios foram plotadas na Figura 1.

\section{RESULTADOS E DISCUSSÃO}

As avaliações da massa seca produzida pelas culturas de cobertura nos dois ensaios foram apresentadas nas Figuras 2A e 2B. A massa seca $\left(\mathrm{t} \mathrm{ha}^{-1}\right)$ produzida no Ensaio I (1,8\% de matéria orgânica) foi inferior àquela produzida no Ensaio II (3,5\%). Na comparação dos somatórios das coberturas, em média, o Ensaio II produziu $16 \%$ a mais que o Ensaio I, em plantio convencional e $15 \%$ a mais no plantio direto.

Maiores valores de palhada foram produzidos, respectivamente, por C. spectabilis, $B$. decumbens, milho e milheto. O pousio da área, com dessecação química, e sem dessecação química, manteve os menores valores de palhada, seguido da testemunha capinada, praticamente sem massa seca.

Na comparação entre os sistemas de plantio, não foram observadas diferenças significativas na massa seca produzida pelas espécies de cobertura e nem nos pousios (Tukey, $\mathrm{P} \leq 0,05 \%$ ).

Tabela 2. Relação das culturas de cobertura que foram utilizadas em dois ensaios com diferentes teores de matéria orgânica do solo.

\begin{tabular}{cccc}
\hline N. & Culturas de cobertura & N. & Culturas de cobertura \\
\hline 1 & Alqueive (testemunha capinada) & 5 & Brachiaria decumbens \\
2 & Pousio com dessecação & 6 & Milho híbrido 'Fórmula' \\
3 & Pousio sem dessecação & 7 & Milheto w 'ADR 300' \\
4 & Crotalaria spectabilis & & \\
\hline
\end{tabular}




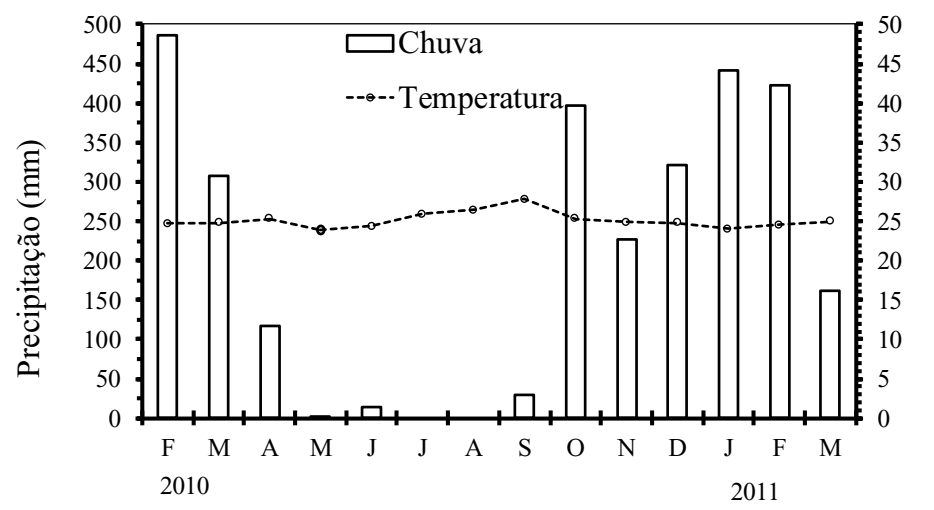

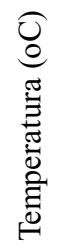

Figura 1. Precipitação mensal e temperatura média registradas no período de condução dos ensaios.
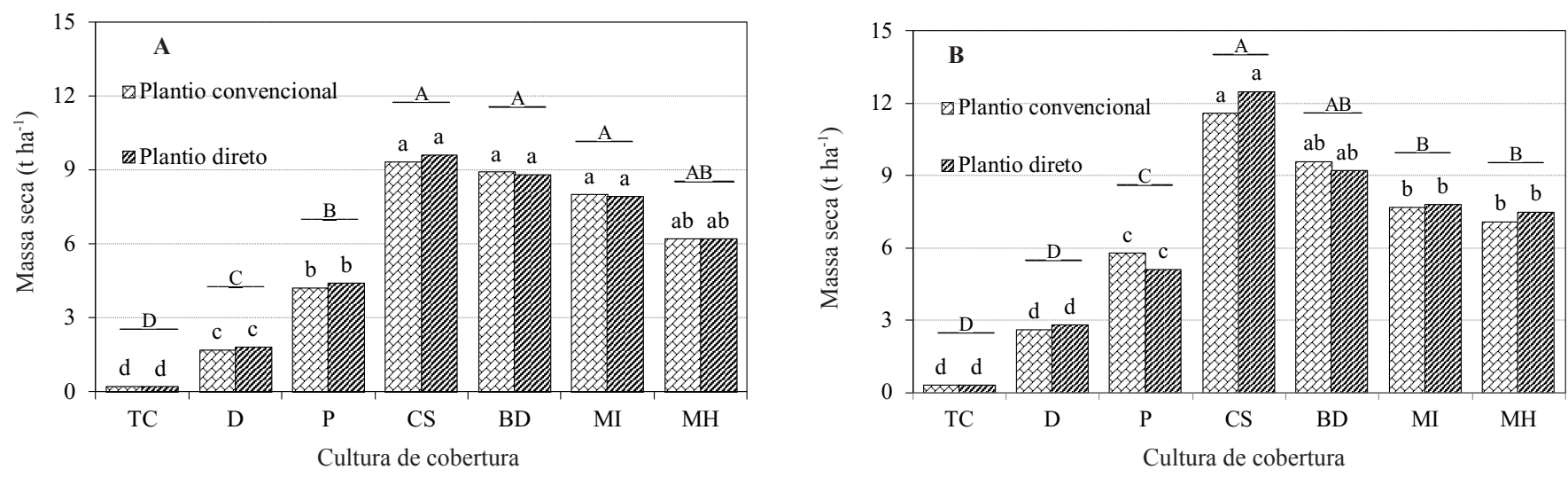

Figura 2. Massa seca de culturas de cobertura em pré-plantio da soja, relativo aos ensaios com 1,8\% de matéria orgânica (2A) e 3,5\% de matéria orgânica (2B), na testemunha capinada (TC), pousio com dessecação (D), pousio sem dessecação (P), Crotalaria spectabilis (CS), Brachiaria decumbens (BD), milho (MI) e milheto (MH). Médias seguidas de mesma letra maiúscula (comparação entre tratamentos) ou minúscula (comparação entre sistemas de plantio), não diferem entre si, pelo teste de Tukey, a $5 \%$ de probabilidade.

Na Tabela 3, a análise de variância do Ensaio I indicou efeito significativo das culturas de cobertura sobre P. brachyurus, aos 40 e 70 dias após a emergência (N40 e N70), além de efeitos significativos sobre a massa verde de raízes, a massa seca da parte aérea e o rendimento da soja. Já o sistema de plantio, que também apresentou estes efeitos significativos, somente não influenciou a massa verde de raízes nos 2 ensaios. Na interação entre culturas de cobertura e sistemas de plantio, não houve interação significativa apenas na NT 40, no Ensaio I, e na NT 40 e NT 70, no Ensaio II.

Os dados obtidos corroboram as informações de Altmann (1), Costa (4), Goulart (10) e Inomoto et al. (15) que citam os benefícios de culturas de cobertura, como antagonistas e ideais para a recomendação em rotação ou consorciação. Além disso, segundo estes autores, o P. brachyurus reduz o seu nível populacional o suficiente para se reproduzir adequadamente, quando utilizadas estas culturas de cobertura. A matéria orgânica do solo também contribui com este manejo, segundo Rodriguez-Kábana \& Canullo (21) e Costa (4), existindo uma constante liberação de nutrientes para o desenvolvimento radicular em profundidade. Há também a possibilidade da matéria orgânica alterar a fisiologia do hospedeiro, com maior resistência, e permitir também o desenvolvimento de microrganismos antagonistas, segundo Rodriguez-Kábana et al. (22).

As avaliações do nematoide/200 cc de solo $+5 \mathrm{~g}$ de raízes, foram plotadas nas Figuras 3A e 3B, para os 40 dias após a emergência (40 DAE), e nas Figuras 4A e 4B, para os 70 dias após a emergência (70 DAE). Houve controle efetivo promovido pelos tratamentos, exceto quando utilizado milho (híbrido 'Formula'), o qual apresenta sucetibilidade ao parasita, e o pousio sem dessecação, onde houve predominância das plantas daninhas capim colchão (Digitaria horizontalis), capim marmelada (Brachiaria plantaginea) e leiteiro (Euphorbia heterophylla). A C. spectabilis reduziu os nematoides em 92\% no Ensaio I e 91\% no Ensaio II, em média, aos 40 DAE.

Praticamente não se observam efeitos dos sistemas de plantio, quando as culturas de cobertura já são efetivas sobre os níveis populacionais de P. brachyurus, assim, o revolvimento na época do plantio pouco contribuiu para a redução populacional. Isto pode ser explicado pelo pouco tempo deixado sem plantas após o revolvimento, sendo logo em seguida semeadas as culturas. Por outro lado, quando houve pousio não dessecado e milho, o plantio convencional, com grade aradora, contribuiu para reduzir os níveis do nematoide.

Embora ocorra rápida diminuição da população, a utilização de plantio convencional, com revolvimento do solo, parece não ser adequado, pois segundo Debiasi et al. (5), apesar de se obter os melhores resultados de controle, se comparado a consórcios e plantios de crotalárias, não se recomenda esta estratégia, em função dos efeitos negativos desta prática na qualidade do solo. A sua utilização também não é recomendada por Inomoto (12).

O teor de matéria orgânica dos ensaios também reduziu os níveis populacionais nos tratamentos que já eram efetivos. Assim, a supressão de nematoides pela matéria orgânica tem sido atribuída à melhoria dos solos, incluindo melhor produção de agregados que liberam elementos nutricionais periodicamente, além de boa retenção de umidade, aeração 
Tabela 3. Valores de F calculados pela análise de variância para os resultados do ensaio I (1,8\% de matéria orgânica) e do ensaio II (3,5\% de matéria orgânica) de número de nematoides aos 40 dias após a emergência (N40) e 70 dias após a emergência (N70), massa verde de raízes (R), massa seca de parte aérea (A) e rendimento de soja $(\mathrm{RE})$.

\begin{tabular}{lccccc}
\hline \multicolumn{7}{c}{ Ensaio I: $1,8 \%$ de matéria orgânica } & & & \\
\hline Causas da variação & N40 & N70 & $\mathrm{R}$ & $\mathrm{A}$ & $\mathrm{RE}$ \\
\hline Cultura de cobertura - CC & $5,28^{*}$ & $6,12^{*}$ & $6,91^{*}$ & $7,19^{*}$ & $16,38^{* *}$ \\
Sistema de plantio - SP & $5,31^{*}$ & $6,39^{*}$ & $2,84 \mathrm{~ns}$ & $7,39^{*}$ & $6,19^{*}$ \\
CC x SP & $1,04 \mathrm{~ns}$ & $11,58^{* *}$ & $7,38^{*}$ & $5,73^{*}$ & $11,64^{* *}$ \\
CV $(\%)$ & 23,19 & 17,32 & 5,39 & 9,17 & 6,05 \\
\hline & Ensaio II: $3,5 \%$ de matéria orgânica & & & \\
\hline Causas da variação & N40 & N70 & R & A & RE \\
\hline Cultura de cobertura - CC & $11,47^{* *}$ & $5,36^{*}$ & $2,17 \mathrm{~ns}$ & $10,39 * *$ & $6,38^{*}$ \\
Sistema de plantio - SP & $3,92^{*}$ & $3,84 *$ & $1,48 \mathrm{~ns}$ & $7,38^{*}$ & $7,31^{*}$ \\
CC x SP & $2,28 \mathrm{~ns}$ & $2,04 \mathrm{~ns}$ & $10,53 * *$ & $9,53 * *$ & $9,63^{* *}$ \\
\hline CV $(\%)$ & 17,27 & 16,20 & 7,29 & 12,15 & 9,26 \\
\hline
\end{tabular}

ns, *, ** não significativo, significativo a $5 \%$ e a $1 \%$ de probabilidade pelo teste $\mathrm{F}$, respectivamente.
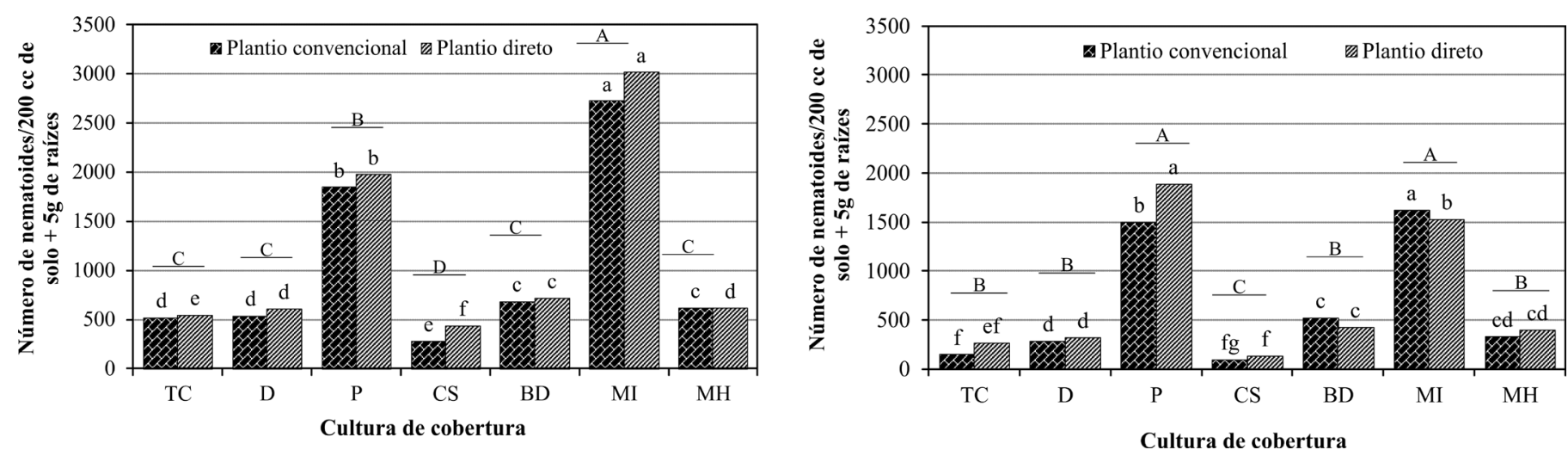

Figura 3. Número médio de nematoides aos 40 dias após a emergência da cultura (40 DAE), relativo aos ensaios com 1,8\% de matéria orgânica (3A) e 3,5\% de matéria orgânica (3B), na testemunha capinada (TC), pousio com dessecação (D), pousio sem dessecação (P), Crotalaria spectabilis (CS), Brachiaria decumbens (BD), milho (MI) e milheto (MH). Médias seguidas de mesma letra maiúscula (comparação entre tratamentos) ou minúscula (comparação entre sistemas de plantio), não diferem entre si, pelo teste de Tukey, a $5 \%$ de probabilidade.
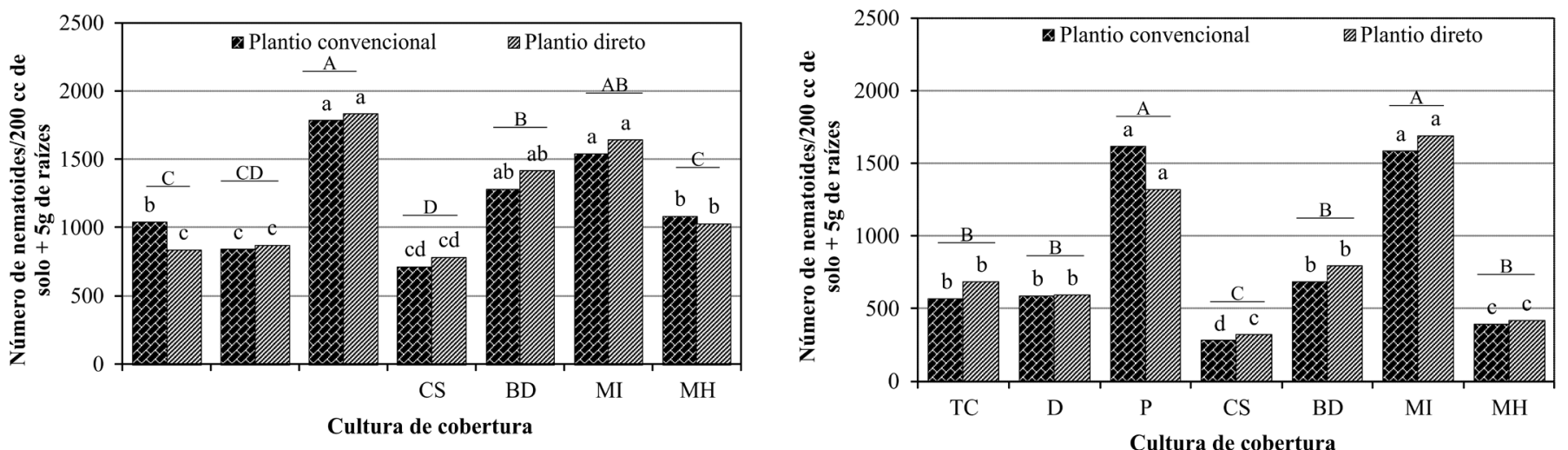

Figura 4. Número médio de nematoides aos 70 dias após a emergência da cultura (70 DAE), relativo aos ensaios com 1,8\% de matéria orgânica (4A) e 3,5\% de matéria orgânica (4B), na testemunha capinada (TC), pousio com dessecação (D), pousio sem dessecação (P), Crotalaria spectabilis (CS), B. decumbens (BD), milho (MI) e milheto (MH). Médias seguidas de mesma letra maiúscula (comparação entre tratamentos) ou minúscula (comparação entre sistemas de plantio), não diferem entre si, pelo teste de Tukey, a 5\% de probabilidade. 
e produção de microrganismos antagônicos aos nematoides, como observado por Costa (4) e McSorley (18).

Estes benefícios, contudo, são dependentes da relação $\mathrm{C} / \mathrm{N}$ da cultura de cobertura, permitindo uma liberação gradual de nutrientes, como citado por Teixeira et al. (24). Segundo Miotto, et al. (19), em estudos com Crotalaria juncea, a liberação de nitrogênio é rápida (maior parte até os 45 dias após o corte), da mesma forma que o potássio, contidos na fitomassa.

Embora a população inicial de $P$. brachyurus da área mais pobre em matéria orgânica tenha sido $13 \%$ maior que a de 3,5\% de matéria orgânica, antes da instalação das culturas de cobertura, as avaliações da soja aos 40 DAE apresentaram-se com um valor significativamente maior nesta área, provavelmente devido à menor resistência das plantas à multiplicação e à menor taxa de microrganismos antagonistas. Estes efeitos também foram observados aos 70 DAE.

A testemunha capinada e o pousio com dessecação evitaram a multiplicação, contudo mantiveram níveis consideráveis do nematoide, sobreviventes. Assim, os restos de raízes de soja da safra anterior no perfil de solo não foram eliminados através de capina ou dessecação, mantendo considerável inóculo para aumento ao longo do desenvolvimento da soja, nas avaliações de 40 e 70 DAE.

O milheto apresentou uma leve multiplicação de $P$. brachyurus, embora seja uma cobertura de solo muito indicada para se reduzir esse nematoide, assim, há fortes indícios de que os fatores edafo-climáticos tenham tido interferência sobre os níveis de resistência dessa espécie vegetal. Salientam-se, contudo, os efeitos na formação de perfil de solo com matéria orgânica e o bom desenvolvimento radicular em profundidade, o que contribui para o desenvolvimento da cultura principal, assim como recomendado por Inomoto (12). Já o milho, se comportou semelhantemente ao pousio sem dessecação, onde houve altos índices de infecção de nematoides nas raízes da soja.

Nos níveis intermediários de redução populacional, esteve $B$. decumbens, o que sugere que possa ter sido um tempo de manutenção desta cobertura insuficiente para reduzir os níveis populacionais, necessitando talvez mais tempo para obter efeitos. Contudo, há muitos estudos contraditórios sobre os efeitos desta cultura de cobertura sobre populações de $P$. brachyurus. Os dados mostram fatores de reprodução na faixa de 2 a 4, como observado por Dias-Arieira (6), que realizou os estudos em casa de vegetação. Em campo, têm sido observadas maiores populações, mas com os benefícios de grande volume de palhada, como citados por Stanton et al. (23).

Os níveis populacionais de $P$. brachyurus observados na segunda avaliação (70 DAE) apresentaram uma tendência de equilíbrio, com aumento naqueles tratamentos onde antes houve antagonismo, e diminuição onde havia facilidade de multiplicação de $P$. brachyurus, o que sugere, novamente, o efeito dos fatores edafo-climáticos, com temperaturas altas e grande precipitação. Este fator nos leva a observar que estas condições tendem a facilitar o aumento dos níveis
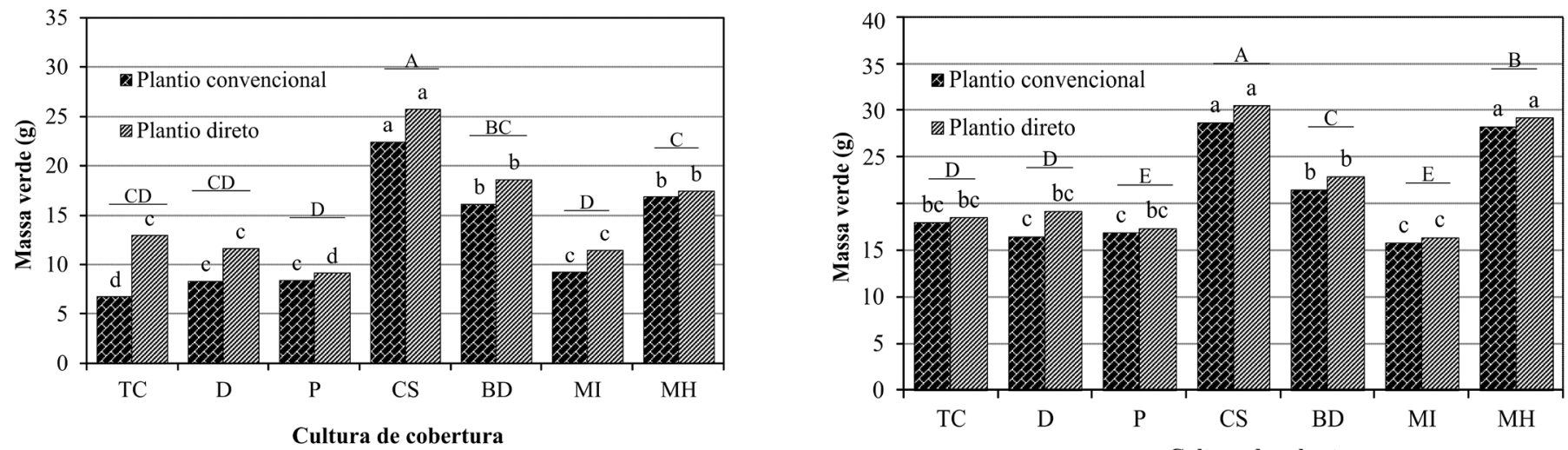

Cultura de cobertura

Figura 5. Massa verde de raízes relativa aos ensaios com 1,8\% de matéria orgânica (5A) e 3,5\% de matéria orgânica (5B), na testemunha capinada (TC), pousio com dessecação (D), pousio sem dessecação (P), Crotalaria spectabilis (CS), Brachiarua decumbens (BD), milho (MI) e milheto (MH). Médias seguidas de mesma letra maiúscula (comparação entre tratamentos) ou minúscula (comparação entre sistemas de plantio), não diferem entre si, pelo teste de Tukey, a 5\% de probabilidade.
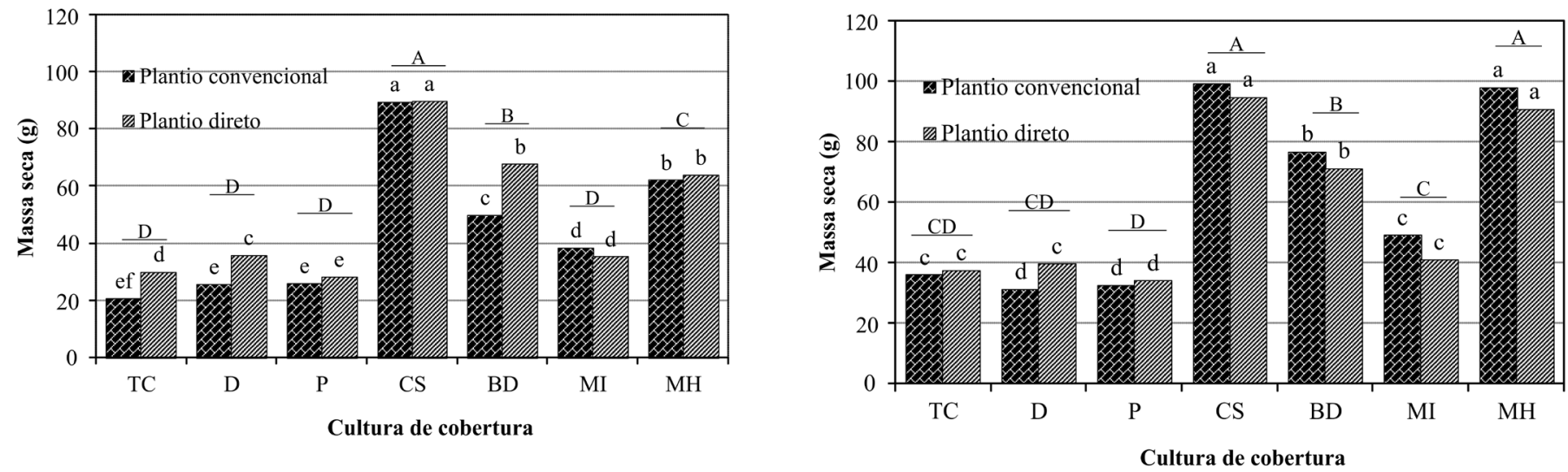

Figura 6. Massa seca de parte aérea relativa aos ensaios com 1,8\% de matéria orgânica (6A) e 3,5\% de matéria orgânica (6B), na testemunha capinada (TC), pousio com dessecação (D), pousio sem dessecação (P), Crotalaria spectabilis (CS), Brachiarua decumbens (BD), milho (MI) e milheto (MH). Médias seguidas de mesma letra maiúscula (comparação entre tratamentos) ou minúscula (comparação entre sistemas de plantio), não diferem entre si, pelo teste de Tukey, a $5 \%$ de probabilidade. 

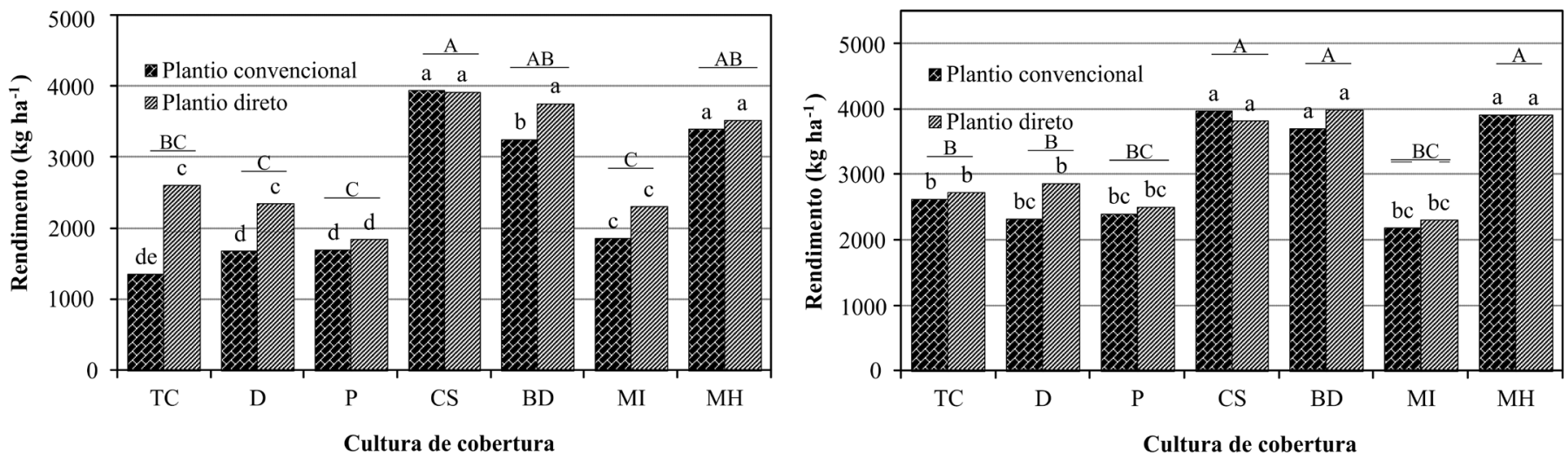

Figura 7. Rendimento de grãos de soja relativo aos ensaios com 1,8\% de matéria orgânica (7A) e 3,5\% de matéria orgânica (7B), na testemunha capinada (TC), pousio com dessecação (D), pousio sem dessecação (P), Crotalaria spectabilis (CS), Brachiaria decumbens (BD), milho (MI) e milheto (MH). Médias seguidas de mesma letra maiúscula (comparação entre tratamentos) ou minúscula (comparação entre sistemas de plantio), não diferem entre si, pelo teste de Tukey, a 5\% de probabilidade.

populacionais, mesmo em se tratando de utilização de sistemas eficazes para a redução populacional, e dificultando o manejo destes parasitas.

Resultados semelhantes foram discutidos por Goulart (10), sobre os aspectos que influenciam o desenvolvimento deste nematoide nas condições tropicais. Ressalta-se por isso, a necessidade de fortalecermos a formação de palhada e matéria orgânica no perfil de solo, para que as raízes sejam produzidas em maiores profundidades. Também deve-se priorizar o manejo da fertilidade em profundidade de solo e a escolha de uma variedade de soja que apresente algum nível de resistência.

As avaliações aos 70 DAE mostraram que o plantio direto reduziu as populações, contudo, nas áreas onde os níveis iniciais eram altos, houve manutenção de altos níveis, o que contribuiu para reduzir a produtividade da soja. Assim, a comparação entre os métodos de preparo de solo sugere que o preparo convencional inicialmente expõe as raízes e reduz a população, mas não a elimina, e quando ocorre o desenvolvimento da cultura, há uma falta de antagonistas do solo, o que concorre para o aumento dos níveis.

Assim, se utilizadas culturas de cobertura com diferentes relações $\mathrm{C} / \mathrm{N}$, dentro de um programa de aumento de matéria orgânica em profundidade e/ou antagonismo, permite uma ferramenta a mais no manejo, como discutido anteriormente. Estes resultados estão em consonância com os argumentos de Rodriguez-Kábana et al. (22), em trabalhos desenvolvidos com culturas de inverno.

As culturas de cobertura tiveram efeitos significativos sobre a massa verde (Figuras 5A e 5B) e a massa seca de parte aérea da soja (Figuras 6A e 6B). Quando a cobertura de solo apresentou algum efeito, este foi notado nas duas variáveis avaliadas. Assim, a $C$. spectabilis foi a mais significativa em beneficiar esta cultura, seguido de milheto e $B$. decumbens.

A escolha da área com maiores níveis de matéria orgânica teve média interferência sobre o crescimento vegetativo e a soja apresentouse com maior massa, onde havia plantas antagonistas. As maiores diferenças (teste de Tukey, $\mathrm{P} \leq 0,05 \%$ ) entre plantio convencional e direto foram observadas na área de 1,8\% de matéria orgânica, onde o plantio direto teve benefícios sobre os componentes do desenvolvimento da soja.

Os dados obtidos foram refletidos na produtividade da soja, com significativo benefício das culturas de cobertura de solo, nos dois ensaios (Figuras 7A e 7B). As maiores respostas das coberturas ocorreram onde havia $3,5 \%$, onde a média geral de produtividade foi $22,6 \%$ superior no plantio convencional e $8,7 \%$ no plantio direto.

Neste experimento, conclui-se que as dificuldades enfrentadas com
P. brachyurus podem ser planejadas por meio de ações que reduzam os níveis populacionais, e concomitantemente, podem ser utilizados processos contínuos de estímulo ao desenvolvimento radicular. Observaram-se também, que as condições de campo podem interferir sobre os fatores de reprodução de espécies vegetais, na presença de altas densidades populacionais deste parasita.

\section{REFERÊNCIAS BIBLIOGRÁFICAS}

1. Altmann, N. Plantio direto no Cerrado: 25 anos acreditando no sistema. Passo Fundo: Aldeia Norte Editora, 2010. 568 p.

2. Asmus, G. L. Distribuição quali-quantitativa de nematoides fitoparasitos em áreas de produção de algodão em Mato Grosso do Sul. In: Congresso Brasileiro do Algodão, 4., 2003, Goiânia. Anais. Goiânia: EMBRAPA, 2003. p. 142-143.

3. Coolen, W. A.; D'Herde, C. J. A method for the quantitative extraction of nematodes from plant tissue. Ghent: State Agriculture Research Centre, $1972.77 \mathrm{p}$.

4. Costa, M. J. N. Nematoides: consorciação e rotação de culturas. In: Paterniani, M. E. A. G.; Duarte, A. P.; Tsunechiro, A. Diversidade e inovações na cadeia produtiva de milho e sorgo na era dos transgênicos. Campinas: Instituto Agronômico, Associação Brasileira de Milho e Sorgo, 2012, p. 367-378.

5. Debiasi, H.; Morais, M. T.; Franchini, J. C.; Dias, W. P.; Silva, J. F. V.; Ribas, N. R. Manejo do solo para controle cultural do nematoide das lesões radiculares na entressafra da soja. In: Congresso Brasileiro de Ciência do Solo, 33., 2012, Uberlândia. Anais. Viçosa: UFV, 2012, p. 26-29.

6. Dias-Arieira, C.; Ferraz, S.; Ribeiro, R. C. F. Reação de gramíneas forrageiras a Pratylenchus brachyurus, Nematologia Brasileira, Piracicaba, v. 33, n. 1, p. 90-93. 2008.

7. Dias, W. P.; Asmus, G. L.; Silva, J. F. V.; Garcia, A.; Carneiro, G. E. S. Nematoides. In: Almeida, A. M. R.; Seixas. Soja: doenças radiculares e de hastes e inter-relações com o manejo do solo e da cultura. Embrapa Soja: Londrina, 2010. p. 173-206.

8. Flegg, J. J.; Hooper, D. J. Extraction of free-living stages from soil. In: Southey, J. F. Laboratory methods for working with plant and soil nematodes. London: Ministry of Agriculture, Fisheries and Food, 1970. 148p.

9. Gonzaga, V. J. M.; Soares, P. L. M. Chave ilustrada para a identificação das seis espécies de Pratylenchus mais comuns no Brasil. Piracicaba, 2012. Disponível em <http://nematologia.com.br/wp-content/uploads/2012/08/ chavigo.pdf. $>$ Acesso em 14/11/2012.

10. Goulart, A. M. C. Aspectos gerais sobre nematoides-das-lesões-radiculares (gênero Pratylenchus). Planaltina: Embrapa Cerrados, 2008. 30p (Documentos).

11. Handoo, Z. A.; Golden, A. M. A key and diagnostic compendium to the species of the genus Pratylenchus Filipjev, 1936 (Lesion nematodes). Journal of Nematology, Lawrence, v. 21, n. 2, p. 202-218, 1989. 
12. Inomoto, M. M. Importância e manejo de Pratylenchus brachyurus. Revista Plantio Direto, Passo Fundo, v. 108, n. 18, p. 4-9, 2008.

13. Inomoto, M. M.; Asmus, G. L. Host status of graminaceous cover crops for Pratylenchus brachyurus. Plant Disease, St. Paul, v. 94, n. 8, p. 10221025, 2010.

14. Inomoto, M. M.; Machado, A. C. Z.; Antedomênico, S. R. Reação de Brachiaria spp. e Panicum maximum a Pratylenchus brachyurus. Fitopatologia Brasileira, Brasília, v. 32, n. 4, p. 341-344, 2007.

15. Inomoto, M. M.; Motta, L. C. C.; Machado, A. C. Z.; Sazaki, C. S. S. Reação de dez coberturas vegetais a Pratylenchus brachyurus. Nematologia Brasileira, Piracicaba, v. 30, n. 2, p. 151-157, 2006.

16. Jenkins, W. R. A rapid centrifugal-flotation technique for separating nematodes from soil. Plant Disease Reporter, Saint Paul, v. 48, n. 9, p. 692-695, 1964.

17. Machado, A. C. Z.; Motta, L. C. C.; Siqueira, K. M. S.; Ferraz, L. C. C.; Inomoto, M. M. Host status of green manures for two isolates of Pratylenchus brachyurus in Brazil. Nematology, Leiden, v. 9, n. 6, p. 799-805, 2007.

18. Mcsorley, R. Multiple cropping systems for nematode management: a review. Soil and Crop Science, Gainesville, v. 60, n. 3, p. 132-142. 2001.

19. Miotto, A.; Predebon, R.; Wildner, L. P.; Denardin, R. B. N.; Gatiboni, L. C.; Giuriatti, A. Comportamento da cobertura solo durante a decomposição da fitomassa de Crotalaria juncea L. em condições de campo. In: Congresso Brasileiro de Ciência do Solo, 31., 2007, Gramado. Anais. Viçosa: UFV,
2007, p. 107.

20. Ribeiro, N. R.; Dias, W. P.; Homechin, M.; Silva, J. F. V.; Francisco, A. Avaliação da reação de espécies vegetais ao nematoide das lesões radiculares. In: Reunião de Pesquisa de Soja da Região Central do Brasil, 30., 2007, Rio Verde. Anais. Campo Grande: Uniderp: Embrapa Soja, 2007.

21. Rodriguez-Kábana, R.; Canullo, G. H. Cropping systems for the management of phytonematodes. Phytoparasitica, Rehovot, v. 20, n. 3, p. 211-224. 1992.

22. Rodriguez-Kábana, R.; Kokalis-Burelle, N.; Robertson, D. G.; King, P. S.; Wells, L. W. Rotations with coastal bermudagrass, cotton, and bahiagrass for management of Meloidogyne arenaria and southern blight in peanut. Journal of Nematology, Hanover, v. 26, n. 4, p. 665-668. 1994.

23. Stanton, J. M.; Siddiqi, M. R.; Lenne, J. M. Plant parasitic nematodes associated with tropical pastures in Colombia. Nematropica, DeLeon Springs, v.19, n.25, p.169-175, 1989.

24. Teixeira, C. M.; Carvalho, G. J.; Andrade, M. J. B.; Silva, C. A.; Pereira, J. M. Decomposição e liberação de nutrientes das palhadas de milheto e milheto + crotalária no plantio direto do feijoeiro. Acta Scientiarum, Maringá, v. 31, n. 4, p. 647-653, 2009.

25. Tihohod, D. Guia prático para a identificação de fitonematoides. Jaboticabal: FCAV, FAPESP, 1997. 246 p

26. Yagi, R.; Ferreira, M. E.; Cruz, M. C. P.; Barbosa, J. C.; Araujo, L. A. N. Soil organic matter as a function of nitrogen fertilization in crop successions. Scientia Agricola, Piracicaba, v. 62, n. 4, p. 374-380, 2005. 